\title{
Design and Calibration of a device solving the interface issues between tenax tubes and gas sensor arrays
}

\author{
G. Pennazza ${ }^{1}$, M. Santonico ${ }^{2}$, R. Capuano ${ }^{2}$, P. Prisco ${ }^{2}$, C. Di Natale ${ }^{2}$, A. D’Amico $^{2}$, \\ $U$-BIOPRED study \\ ${ }^{1}$ Center for Integrated Research - CIR, Unit of Electronics for Sensor Systems, "Università Campus \\ Bio-Medico di Roma"; Via Alvaro del Portillo 21,00128 Roma, Italy, \\ g.pennazza@unicampus.it \\ ${ }^{2}$ Department of Electronic Engineering, University of Rome Tor Vergata; Via del Politecnico 1, 00133 \\ Rome, Italy.
}

\begin{abstract}
:
Tenax tubes are adsorbent cartridges commonly used in Gaschromatographic (GC) analyses with preconcentration purposes. Thus many devices are commercially available to desorb tenax tubes into the GC inlet. The use of tenax tubes as sampling medium is also suitable for the analysis of volatile mixture with gas sensor arrays. This application rises up an interface problem which is faced by the present work with a desorption device designed and calibrated on the basis of theoretical models. These models are calculated on the characteristics of selected volatile compounds present in the exhaled breath. In fact, tenax tubes could be of main interest in breath analysis.
\end{abstract}

Key words: gas sensor array, tenax, volatile compounds, preconcentration, exhaled breath.

\begin{abstract}
Introduction
Tenax GR datasheet [1] gives the breakthrough volume data calculated in a temperature range from $20^{\circ} \mathrm{C}$ to $300^{\circ} \mathrm{C}$ for 120 organic compounds. These data are commonly used for routine analyses using tenax tubes by Gaschromatographic instruments including a temperature and flow control of the inlet and of the column. In fact sampling techniques based on adsorbent cartridges have been ad hoc designed for such instruments, but they could be useful for other chemical sensor systems, such as non-selective gas sensors array, adding preconcentration ability and improving storage and delivery actions. Besides, gas sensors array technology is often based on flow and temperature constraints not matched with tenax desorption requirements. This study proposes some theoretical data suitable to realize an ad hoc desorption process of a tenax cartridge into a sensor measure chamber. This data could be exploited for gas sensor arrays application in breath analysis; in fact, tenax cartridges are a more suitable sampling mean for exhaled breath with respect to bags, which cannot be stored or easily transported.
\end{abstract}

\section{Materials and Methods}

A list of compounds present in the exhaled breath [2] has been used for this study, because non selective gas sensor arrays are often used in medical applications oriented to a non invasive diagnosis of respiratory diseases $[3,4]$. In order to design a desorbing unit linking the tenax tube and the sensors chamber, flow and temperature are the most meaningful parameters to be controlled. To this purpose retention times (rt) have been calculated for each of the selected compounds present in the human exhaled breath (reported in figure 1 and figure 2 ) in a temperature (T) range from $20^{\circ} \mathrm{C}$ to $300^{\circ} \mathrm{C}$ starting from the given breakthrough volume data at a constant flow of $40 \mathrm{ml} / \mathrm{min}$. These rts have been fitted obtaining a curve $(T, r t)$ for each compound.

\begin{tabular}{|l|l|l|}
\hline Hydrocarbons & Alcohols and Glycols & \multicolumn{1}{c|}{ Aldehydes and Ketones } \\
\hline Methane & Methanol & Acetone \\
\hline Ethane & Ethanol & 2-Methyl Propanal \\
\hline Propane & 2-Propanol & 2-Butanone \\
\hline Butane & 1-Propanol & 2-Pentanone \\
\hline Pentane & 2-Butanol & 3-Methyl Butanal \\
\hline Hexane & 1-Butanol & 3-Pentanone \\
\hline Heptane & 1-Pentanol & Hexanal \\
\hline Octane & Hexanol & 4-Heptanone \\
\hline Nonane & & 2-Heptanone \\
\hline Decane & & Heptanal \\
\hline Dodecane & & Octanal \\
\hline Tetradecane & & Nonanal \\
\hline Hexadecane & & \\
\hline Octadecane & & \\
\hline Eicosane & & \\
\hline
\end{tabular}

Fig. 1. Compounds selected for the elaboration of the model. Family compounds: hydrocarbons, Alcohols, Glycols, Aldehydes, Ketones. 


\begin{tabular}{|l|l|}
\hline \multicolumn{1}{|c|}{ Halogens } & \multicolumn{1}{c|}{ Aromatic compounds and Terpenes } \\
\hline Methylenechloride & Benzene \\
\hline Tetrachloroethylene & Toluene \\
\hline 1,3-Dichlorobenzene & Naphthalene \\
\hline $1,4-$ Dichlorobenzene & Phenol \\
\hline 1,2 -Dichlorobenzene & Ethylbenzene \\
\hline & Limonene \\
\hline & P-Xylene \\
\hline & m-Xylene \\
\hline & o-Xylene \\
\hline & $1,3,5-$ Trimethylbenzene \\
\hline & Benzaldehyde \\
\hline & Biphenyl \\
\hline & \\
\hline & \\
\hline & \\
\hline &
\end{tabular}

Fig. 2. Compounds selected for the elaboration of the model. Family compounds: halogens, aromatic compounds, terpenes.

\section{Results}

Figure 3 shows the model calculated for 15 of the selected compounds belonging to the hydrocarbons family compounds among the five reported in figures 1 and 2 .
As an example, a line corresponding to 200 seconds of $\mathrm{rt}$ has been evidenced. This time interval represents the typical duration of a gas sensor array measurement. The intercept of this line with each curve highlights the temperature necessary for the desorption of the related compound at that time. Thus the temperature values intercepted by this line could be used for the definition of a temperature profile for the control of the thermal desorption process.

As example, exploiting the data reported in figure 3 , the parameters for pentane can be calculated as following. From figure 1 it results that pentane is desorbed from tenax at a temperature of $20^{\circ} \mathrm{C}$ with an rt ranging from 700 to 800 seconds.

\section{Hydrocarbons}

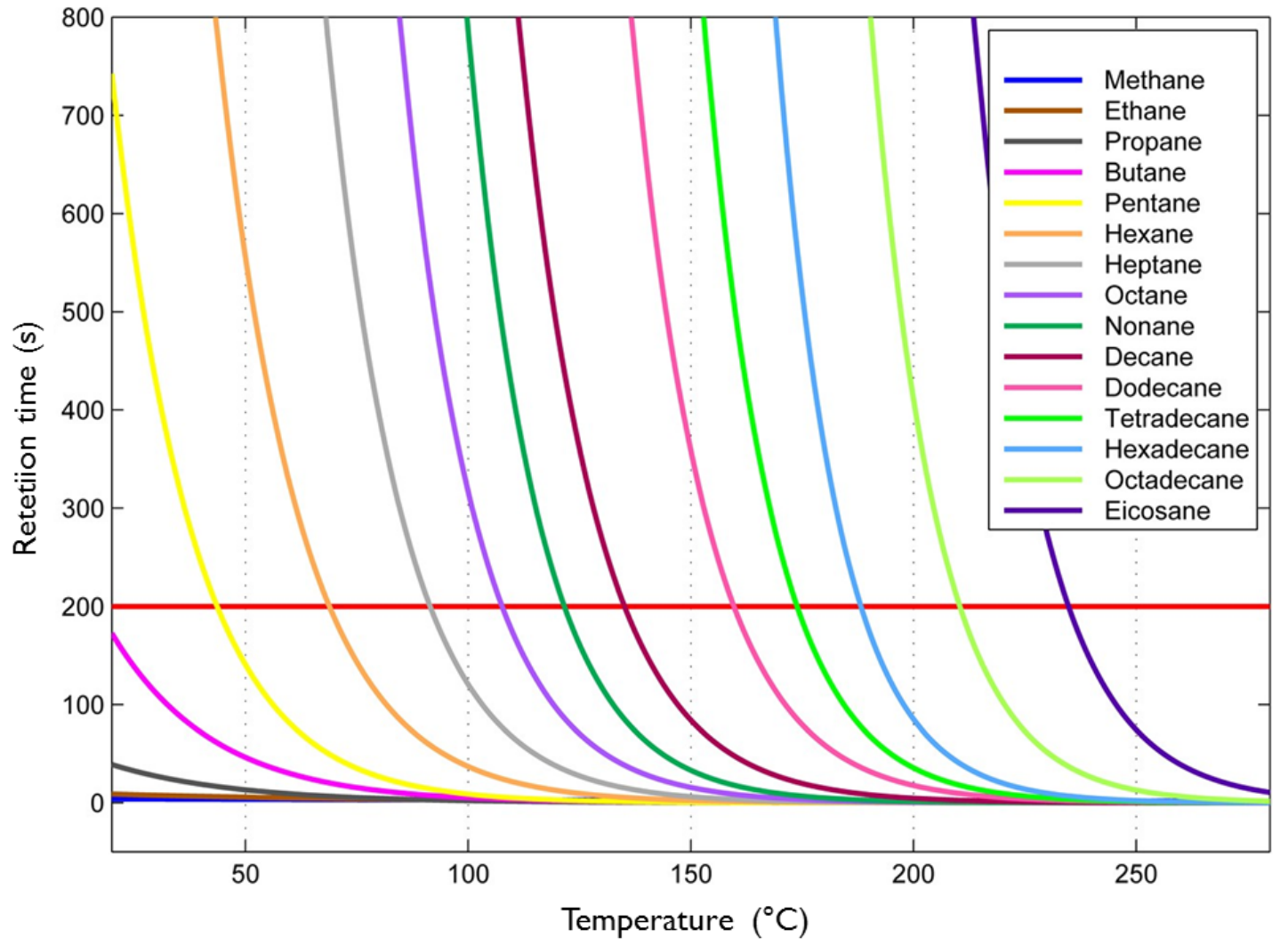

Fig. 3. Tenax GR retention times vs temperature at a costant flow of $40 \mathrm{ml} / \mathrm{min}$ for 15 different hydrocarbons, a family compounds selected as example among the ones listed in figures 1 and 2. The horizontal red line represent the usual time interval of a gas sensor array measurement. 
Thus, heating the tenax tube at a temperature of $50^{\circ} \mathrm{C}$ allows pentane rt to shift in a time interval ranging from 100 to 200 seconds.

On the basis of the models calculated a temperature flow-chart has been designed (figure 4) for the desorption unit to be realized, indicating the best temperature for the different compound families at a fixed flow of $40 \mathrm{ml} / \mathrm{min}$ with an rt of $200 \mathrm{sec}$. This retention time match

\section{Conclusions}

The methodology developed in this works can be used in breath analysis via a gas sensor array, gaining three important improvements: gas sensor array, allowing sample storage and delivery thus improving reproducibility and standardization.

2) The opportunity to use a temperature profile for the desorption process in order to obtain a time separation of different family compounds.

3) Point two should allow the utilization of a gas sensor array with a hybrid approach: which means the non selectivity of the gas sensor array joint with a separation technique realized via a thermally controlled desorption process.

1) The possibility to use tenax tubes instead of sampling bags for exhaled breath collection and measure with a

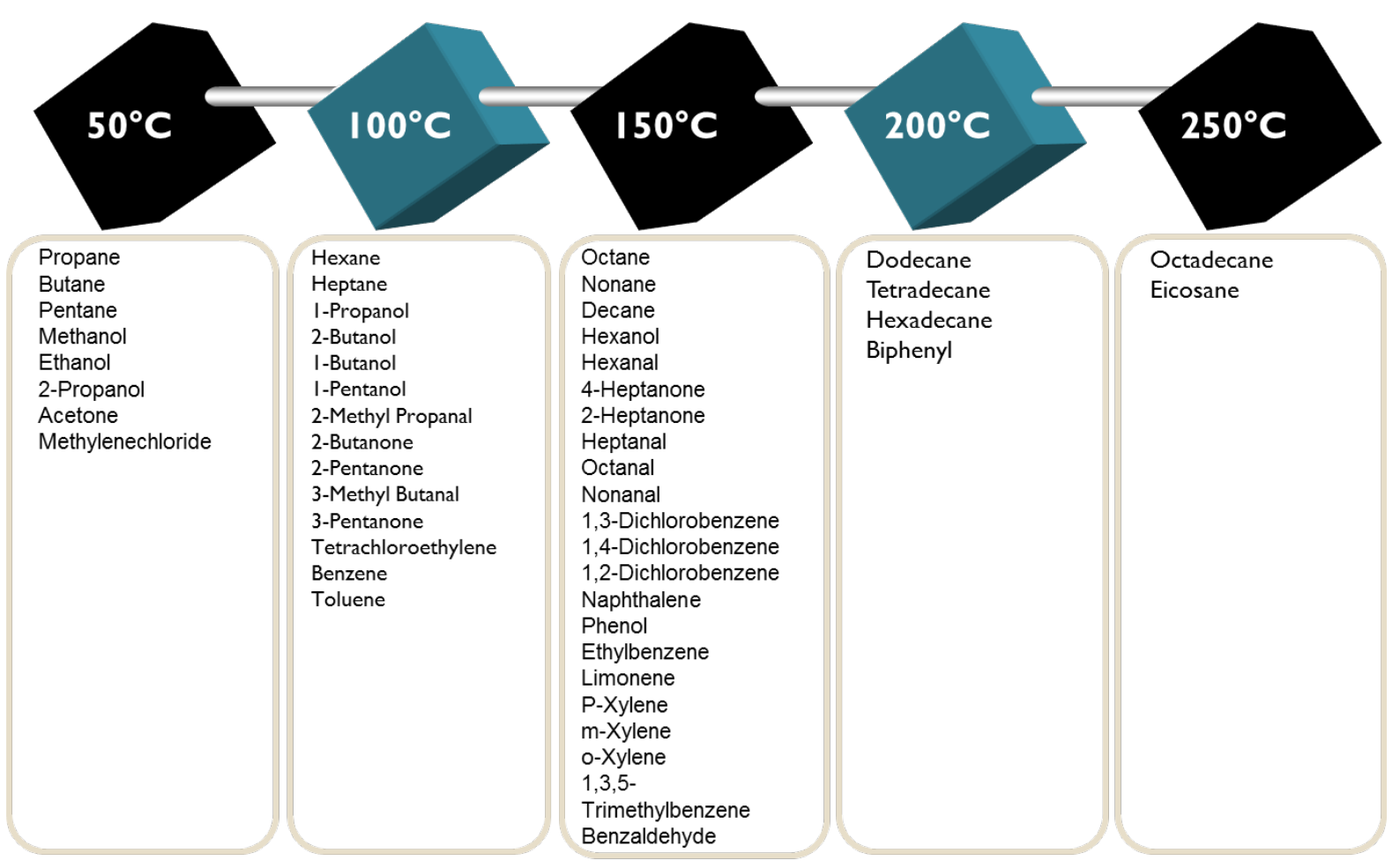

Fig. 4. flow chart of a temperature program to be followed by a desorption unit for Tenax GR tubes in order to separate different compound families.

\section{References}

[1] Tenax ${ }^{\circledR}$ GR adsorbent resin for trapping volatiles. Scientific Instrument Services, Inc. [http://www.sisweb.com/index/referenc/tenaxgrm. $\mathrm{htm}]$

[2] Pennazza G., Santonico M., Martinelli E., et al. Interpretation of exhaled volatile organic compounds. European Respiratory monograph: Exhaled Biomarkers 2010;49, I. Horvath and J.C. de Jongste (Eds.). European Respiratory Society, ISBN: 978-1-84984-004-0.10000.

[3] D'Amico A.,Di Natale C., Paolesse R., Macagnano A., Martinelli E., Pennazza G., Santonico M., et al. (2008). Olfactory systems for medical applications. Sensors and Actuators B, Chemical, vol. 130; p. 458-465.

[4] Dragonieri S., Annema J.T., Schot R., et al. An electronic nose in the discrimination of patients with non-small cell lung cancer and COPD. Lung Cancer 2009; 64 (2): 166-170. 